\section{Percepção dos trabalhadores avulsos sobre os riscos ocupacionais no porto do Rio Grande, Rio Grande do Sul, Brasil}

\author{
Temporary workers' perceptions of occupational \\ risks in the port of Rio Grande, Rio Grande do Sul \\ State, Brazil
}

Jorgana Fernanda de Souza Soares ${ }^{1}$

Marta Regina Cezar-Vaz ${ }^{2}$

Raul Andrés Mendoza-Sassi 3

Tabajara Lucas de Almeida ${ }^{2}$

Ana Luiza Muccillo-Baisch 3

Maria Cristina Flores Soares 3

Valdecir Zavarese da Costa 3

\footnotetext{
1 Departamento de Enfermagem, Fundação Universidade Federal do Rio Grande, Rio Grande, Brasil. 2 Programa de Pós-

Graduação em Enfermagem. Universidade Federal do Rio Grande, Rio Grande, Brasil. 3 Programa de PósGraduação em Ciências da Saúde, Universidade Federal do Rio Grande, Rio Grande, Brasil.

Correspondência J. F. S. Soares Departamento de Enfermagem, Fundação Universidade Federal do Rio Grande. Rua Gal. Osório s/n, 4o andar, Rio Grande, RS 96200-190, Brasil. jfss_rs@hotmail.com
}

\begin{abstract}
This was a cross-sectional, descriptive, quantitative study in the port of Rio Grande, Rio Grande do Sul, Brazil, aimed at identifying occupational risk perceptions in a sample of 306 temporary dockworkers. Most temporary dockworkers (93.46\%) acknowledged the existence of health risks on the job, independently of schooling ( $p$ $=0.44)$ and job activity $(p=0.47)$. Risks identified by temporary workers as a whole included falling of suspended objects ( $8.43 \pm 2.47)$, noise (8.06 \pm 2.32$)$, and bad weather conditions (8.05 \pm 2.48 ). Risks that varied significantly between jobs were: noise $(p=0.00)$, lifting loads manually $(p=0.00)$, work tools ( $p=0,00)$, insufficient number of work team members ( $p=0.03)$, extra wages based on productivity $(p=0.00)$, work pace ( $p=0.01)$, working on scaffolding and other high areas $(p=0.00)$, workers moving on top of cargo ( $p=0.00)$, and ship's ladders and gangways $(p=0.00)$. The study corroborated that temporary dock work is unhealthy and hazardous, and that the risks affect workers according to the specific jobs they perform.
\end{abstract}

Occupational Risks; Occupational Health; Workers

\section{Introdução}

Os seres humanos possuem uma peculiar capacidade de alterar a seu favor o ambiente, bem como para responder a ele, gerando e reduzindo riscos 1 . Na literatura consultada, o risco é assumido como entidade probabilística, fazendo com que a previsão de ocorrência dos agravos não seja indiscutível, incontrolável; os riscos são, na realidade, apenas possibilidades 2 . Para a epidemiologia, o risco é, sinteticamente, a probabilidade de ocorrência de um dado acontecimento relativo à saúde, estimado a partir da ocorrência deste acontecimento em um passado recente 3 . O risco varia de acordo com a percepção de cada indivíduo, porque os seres humanos possuem distintas percepções acerca dos riscos aos quais estão expostos 4 . É dizer que experienciar o risco constitui a variação das diferenças individuais 5 , admitindo-se também que o conhecimento sobre os riscos possui influências das experiências individuais e da construção coletiva do risco, não sendo apenas o resultado da exposição ${ }^{6}$. As explanações anteriores permitem concordar que o estabelecimento do "risco" pode ser objetivo, mas a percepção e aceitação, dependem dos aspectos culturais e pessoais 7 .

Entre os inúmeros riscos, os quais vivenciamse cotidianamente, procurou-se salientar os ocupacionais, porque os seres humanos, dedicam ao trabalho, no mínimo, um terço do seu tempo diário 8 e embora as inovações tecnológicas tenham 
reduzido riscos em alguns setores produtivos, estas também inseriram novos 9 .

Em relação a um contexto particular de análise, o trabalho portuário, identifica-se uma carência de publicações científicas em periódicos indexados no que se refere aos riscos ocupacionais e aos acidentes de trabalho. Na literatura internacional, pode-se visualizar alguns estudos com trabalhadores portuários 10,11,12,13,14,15,16. Já na literatura brasileira, verificou-se um trabalho recente 17 o qual se deteve nos riscos e agravos à saúde dos estivadores.

No contexto portuário brasileiro, a prevenção de doenças e acidentes do trabalho é regulamentada pela Norma Regulamentadora 29 18. Nesta, visualizam-se as normas referentes à segurança e saúde dos trabalhadores na particularidade das operações portuárias, onde constam as medidas obrigatórias de prevenção de acidentes e doenças do trabalho, como se deve atuar nos primeiros-socorros a acidentados, entre outros. Nela, torna-se evidente o trabalho portuário como de risco à saúde e vida dos trabalhadores, porém, não são evidenciados todos os riscos presentes no porto. Assim, tornam-se necessários estudos que evidenciem quais são os riscos a que os trabalhadores estão expostos e principalmente, identificar a percepção dos mesmos acerca destes em seu cotidiano, considerando que a identificação das causas dos acidentes é um pré-requisito necessário para as ações de prevenção ${ }^{19}$. Justifica-se a busca por posicionar os trabalhadores como importantes no processo de identificação dos riscos, porque são eles que os vivenciam em seu cotidiano de trabalho e que vêem em seus corpos a materialização dos riscos, seja devido ao acidente de trabalho típico ou a doença ocupacional.

O presente trabalho justifica-se por ser de conhecimento de todos que o trabalhador portuário realiza as suas atividades em um ambiente muitíssimo perigoso e insalubre, sendo que os riscos aumentam em consonância com a carga movimentada, expondo a saúde do trabalhador a permanente perigo 20 . Os trabalhadores portuários avulsos são aqueles que prestam serviços de forma eventual, sem vínculo empregatício, para várias operadoras portuárias, as quais solicitam esse serviço ao Órgão de Gestão de Mão-de-Obra do Trabalho Portuário Avulso (OGMO) 21. Neste sentido, este estudo enfoca o trabalho portuário e os trabalhadores portuários avulsos do porto do Rio Grande, Rio Grande do Sul, Brasil, tendo como objetivo identificar a percepção destes acerca dos riscos à saúde presentes em seu ambiente de trabalho, considerando as diferentes atividades desenvolvidas.

\section{Método}

Este é um estudo transversal, descritivo, com abordagem quantitativa dos dados, realizado no porto do Rio Grande com trabalhadores portuários avulsos.

No porto do Rio Grande, conforme os dados obtidos junto ao OGMO-Rio Grande (OGMORG), a população efetiva de trabalhadores portuários avulsos em 2004, ano que antecedeu a elaboração do projeto, foi de 758 trabalhadores.

Em primeiro momento, foi realizado um estudo com trinta trabalhadores portuários avulsos, no intuito de realizar um diagnóstico situacional sobre o seu conhecimento dos riscos presentes no ambiente de trabalho, devido à indisponibilidade de dados acerca do objeto do estudo. Os participantes foram selecionados conforme a sua disposição para responder ao instrumento que constava de duas perguntas abertas sobre a existência de riscos no ambiente de trabalho e quais eram estes.

Após este estudo, a amostra da pesquisa foi calculada em 306 trabalhadores portuários avulsos. Para este cálculo, utilizou-se o nível de 95\% de confiança, com a prevalência de conhecimento dos riscos à saúde estimada a partir do diagnóstico situacional em 93\%, com precisão $\pm 3 \%$ e considerando $10 \%$ de perdas. Como o objetivo de identificar a percepção dos trabalhadores portuários avulsos sobre os riscos no ambiente de trabalho associado às atividades por eles desenvolvidas, calcularam-se as sub-amostras: capatazia $(\mathrm{N}=138)$; estiva $(\mathrm{N}=132)$; conferente de carga $(\mathrm{N}=18)$; conserto de carga $(\mathrm{N}=4)$; vigilância de embarcações $(\mathrm{N}=11)$ e a categoria bloco $(\mathrm{N}=3)$. A amostra da pesquisa é do tipo não-aleatória, sendo que participaram do estudo os trabalhadores portuários avulsos que haviam se apresentado para concorrer a uma oportunidade de trabalho no turno.

A entrevista estruturada utilizada para a coleta dos dados foi construída a partir dos resultados obtidos no diagnóstico situacional, complementada pela revisão de literatura e observações espontâneas dos pesquisadores no porto. A entrevista foi composta por questões em escala nominal (escolha simples), na qual os respondentes eram solicitados a escolher uma das opções listadas pelos pesquisadores e em escala contínua (múltipla escolha), quando estes eram solicitados a atribuir uma nota de 0 a 10 a cada um dos itens em consonância com o trabalho desenvolvido por cada categoria de trabalhadores. Foi realizado o estudo piloto para testar a entrevista.

A coleta dos dados foi realizada no primeiro e segundo semestre de 2006, nas proximidades 
dos locais onde ocorre a escalação dos trabalhadores para o turno de trabalho, através da aplicação da entrevista estruturada. Realizou-se o teste $\alpha$ de Crombach, para medir a fidedignidade da mesma, e o resultado obtido foi de 0,73 e 0,92 , respectivamente, para a parte do instrumento composta por escala nominal e escala contínua, em consonância com o disposto na literatura 22.

As variáveis definidas para este estudo foram: (a) características sócio-demográficas, representadas por sexo - idade, tempo de atuação no setor, grau de instrução, estado civil, cor e rendimento financeiro e; (b) conhecimento sobre os riscos existentes no trabalho portuário avulso, investigado através da identificação da existência de diversos riscos no trabalho portuário avulso por parte dos trabalhadores portuários avulsos (Figura 1).

A entrada dos dados foi realizada no programa Epi Info 6.04d (Centers for Disease Control and Prevention, Atlanta, Estados Unidos). Os dados foram analisados em um programa estatístico, utilizando-se o nível de significância $\alpha=$ 0,05 . Os dados em escala nominal foram apresentados através da distribuição de freqüência e analisados estatisticamente através do teste qui-quadrado. Os dados em escala contínua foram apresentados através do cálculo da média e desvio-padrão e analisados estatisticamente através da análise de variância seguida do teste post hoc do tipo LSD de Fisher. Foram verificadas as diferenças nas notas médias atribuídas pelos trabalhadores nas atividades de capatazia, estiva, conferência de carga e vigilância de embarcações, sendo excluídos os consertadores de carga e trabalhadores em bloco para esta análise com o intuito de eliminar a co-linearidade referente ao número de trabalhadores entrevistados nestas categorias de trabalho.

Em relação aos aspectos éticos da pesquisa, respeitando a Resolução no. 196/96 do Conselho Nacional de Saúde, foi solicitado e recebido o consentimento do OGMO-RG para a realização do estudo junto aos trabalhadores portuários avulsos. O trabalho foi aprovado pelo Comitê de Ética em Pesquisa na área da saúde da Fundação Universidade Federal do Rio Grande (Processo $n^{\circ}$. 23116.6779/2005-98) e foi utilizado o consentimento livre e esclarecido do participante, o qual foi obtido previamente à entrevista, sendo assinado em duas vias, uma permanecendo com a entrevistadora para arquivamento junto ao processo da pesquisa e a outra via, com o participante.

\begin{tabular}{|c|c|c|c|}
\hline Físico & Químico & Ergonômico/Psicossocial & Mecânico/Acidentes \\
\hline $\begin{array}{l}\text { Ruídos } \\
\text { Vibrações das } \\
\text { máquinas de } \\
\text { trabalho } \\
\text { Intempéries } \\
\text { (sereno, clima) } \\
\text { Temperaturas } \\
\text { extremas }\end{array}$ & $\begin{array}{l}\text { Substâncias } \\
\text { químicas no ar } \\
\text { Substâncias } \\
\text { químicas líquidas }\end{array}$ & $\begin{array}{l}\text { Levantamento manual de carga } \\
\text { Ferramentas de trabalho } \\
\text { (guindastes, guinchos, empilhadeiras) } \\
\text { Falta de orientação e } \\
\text { supervisão quanto à saúde } \\
\text { Componentes das equipes de } \\
\text { trabalho em número abaixo do ideal } \\
\text { Ganho por produtividade } \\
\text { Ritmo de trabalho } \\
\text { Desconforto ocasionado pelo } \\
\text { uso dos equipamentos de } \\
\text { proteção individual }\end{array}$ & $\begin{array}{l}\text { Condições físicas do } \\
\text { terminal portuário } \\
\text { Queda de objetos } \\
\text { suspensos } \\
\text { Trabalho em altura } \\
\text { Tráfego de máquinas } \\
\text { Deslocamento do } \\
\text { trabalhador sobre } \\
\text { as cargas } \\
\text { Instalações elétricas } \\
\text { Empilhamento de carga } \\
\text { Escadas de acesso às } \\
\text { embarcações }\end{array}$ \\
\hline
\end{tabular}

Nota: construído a partir da classificação do Ministério da Saúde 9. 


\section{Resultados}

Todos os 306 trabalhadores portuários avulsos eram do sexo masculino. Em relação à idade, foi verificado que 98 (32,03\%) trabalhadores encontravam-se na faixa etária entre 49 e 58 anos, e 120 $(39,22 \%)$ atuavam no setor no período entre 20 e 34 anos.

Tabela 1

Dados das características sócio-econômicas dos trabalhadores portuários avulsos entrevistados. Porto do Rio Grande, Rio Grande do Sul, Brasil, 2006.

\begin{tabular}{|c|c|c|}
\hline Variável & $n(N=306)$ * & $\%$ \\
\hline \multicolumn{3}{|l|}{ Idade (anos) } \\
\hline $19-28$ & 35 & 11,44 \\
\hline $29-38$ & 77 & 25,16 \\
\hline $39-48$ & 85 & 27,78 \\
\hline $49-58$ & 98 & 32,03 \\
\hline $59-68$ & 11 & 3,59 \\
\hline \multicolumn{3}{|l|}{ Tempo de atuação (anos) } \\
\hline$<2$ & 7 & 2,29 \\
\hline $2-4$ & 52 & 16,99 \\
\hline $5-9$ & 12 & 3,92 \\
\hline $10-19$ & 95 & 31,05 \\
\hline $20-34$ & 120 & 39,22 \\
\hline$>35$ & 20 & 6,54 \\
\hline \multicolumn{3}{|l|}{ Rendimento financeiro (salários mínimos) ** } \\
\hline$<2$ & 15 & 4,90 \\
\hline $2-4$ & 123 & 40,20 \\
\hline $5-9$ & 78 & 25,49 \\
\hline$>10$ & 78 & 25,49 \\
\hline Ignorado & 12 & 3,92 \\
\hline \multicolumn{3}{|l|}{ Grau de instrução } \\
\hline Analfabeto & 2 & 0,65 \\
\hline Ensino Fundamental incompleto & 110 & 35,95 \\
\hline Ensino Fundamental completo & 55 & 17,98 \\
\hline Ensino Médio incompleto & 34 & 11,11 \\
\hline Ensino Médio completo & 88 & 28,76 \\
\hline Ensino Superior incompleto, completo, pós-graduação & 17 & 5,56 \\
\hline \multicolumn{3}{|l|}{ Estado civil } \\
\hline Solteiro & 87 & 28,43 \\
\hline Casado/União consensual & 174 & 56,87 \\
\hline Separado/Desquitado/Divorciado & 40 & 13,07 \\
\hline Viúvo & 5 & 1,63 \\
\hline \multicolumn{3}{|l|}{ Cor } \\
\hline Branco & 177 & 57,84 \\
\hline Preto & 50 & 16,34 \\
\hline Amarelo & 1 & 0,33 \\
\hline Pardo & 57 & 18,63 \\
\hline Indígena & 21 & 6,86 \\
\hline
\end{tabular}

* Subtotal diferente para a variável rendimento financeiro, com 12 (3,92\%) indivíduos que se recusaram a responder ao questionamento;

** O salário mínimo vigente no período da elaboração do projeto (segundo semestre de 2005) era de $\mathrm{R} \$ 300,00$.
Dos 294 (96,08\%) respondentes à questão sobre aos rendimentos financeiros, $123(40,2 \%)$ receberam de dois a quatro salários-mínimos (Tabela 1). Ainda na Tabela 1, pode-se observar que 110 (35,95\%) trabalhadores possuíam como grau de instrução o Ensino Fundamental incompleto, $174(57,84 \%)$ eram casados ou viviam em união consensual e 177 (57,84\%) se auto-avaliaram como brancos.

Dos 306 entrevistados, 286 (93,46\%) responderam que existem riscos à sua saúde no ambiente de trabalho, enquanto 20 (6,54\%) afirmaram que tais riscos inexistem. Não houve relação entre esta variável e o grau de instrução do trabalhador $(p=0,44)$, tampouco com a categoria profissional ( $\mathrm{p}=0,47)$.

Na Tabela 2, pode-se visualizar as notas médias \pm o desvio-padrão das variáveis referentes aos riscos presentes no ambiente de trabalho em escala contínua. Ainda na Tabela 2, observa-se que a variável queda de objetos suspensos $(8,43 \pm 2,47)$ recebeu média significativamente superior $(p=0,00)$ em relação às demais, com exceção das variáveis ruídos $(8,06 \pm 2,32)$ e intempéries $(8,05 \pm 2,48)$.

Na Tabela 3, pode-se observar que ao ajustar por categoria profissional, as variáveis que se referem aos riscos existentes no trabalho, listadas a seguir, receberam nota média significativamente diferente das atividades ocupacionais.

A variável ruídos $(\mathrm{p}=0,00)$ recebeu nota média significativamente maior dos estivadores $(8,71 \pm 1,85)$ em relação à nota média atribuída pelos trabalhadores em capatazia $(7,51 \pm 2,53)$.

A variável levantamento manual de carga $(\mathrm{p}=0,00)$ recebeu nota média significativamente maior dos trabalhadores em capatazia $(7,19 \pm$ $2,95)$ e estiva $(6,73 \pm 3,21)$ em relação aos conferentes de carga $(3,33 \pm 3,48)$ e trabalhadores em vigilância de embarcações $(2,82 \pm 3,57)$.

$\mathrm{O}$ item ferramentas de trabalho $(\mathrm{p}=0,00)$ recebeu nota média significativamente maior dos trabalhadores em capatazia $(6,01 \pm 3,29)$ e estiva $(5,55 \pm 3,27)$ em relação à dos conferentes de carga $(2,78 \pm 3,64)$ e trabalhadores em vigilância de embarcações $(2,09 \pm 2,74)$.

A variável componentes das equipes de trabalho em número abaixo do ideal $(\mathrm{p}=0,03)$ recebeu nota média significativamente maior dos trabalhadores em vigilância de embarcações $(7,82 \pm 3,37)$, estiva $(6,90 \pm 3,37)$ e capatazia $(6,42$ $\pm 3,28$ ) em relação à nota média dos conferentes de carga $(4,72 \pm 3,04)$.

$\mathrm{O}$ item ganho por produtividade $(\mathrm{p}=0,00)$ recebeu nota média significativamente maior dos trabalhadores em estiva $(6,19 \pm 3,50)$ e capatazia $(5,54 \pm 3,62)$ em relação à atribuída pelos 
Valores médios ( \pm desvio-padrão) das notas atribuídas pelos trabalhadores portuários avulsos aos riscos presentes no ambiente de trabalho. Porto do Rio Grande, Rio Grande do Sul, Brasil, 2006.

\begin{tabular}{|c|c|c|}
\hline Variável & Média \pm desvio padrão & p * \\
\hline & & 0,00 \\
\hline Ruídos & $8,06 \pm 2,32$ & $a b$ \\
\hline Vibrações das máquinas de trabalho & $7,44 \pm 2,80$ & $d$ \\
\hline Intempéries & $8,05 \pm 2,48$ & $a b$ \\
\hline Temperaturas extremas & $7,44 \pm 2,66$ & $d$ \\
\hline Substâncias químicas no ar & $7,34 \pm 2,90$ & $d$ \\
\hline Substâncias químicas líquidas & $6,55 \pm 3,39$ & ef \\
\hline Levantamento manual de carga & $6,55 \pm 3,33$ & ef \\
\hline Ferramentas de trabalho & $5,43 \pm 3,43$ & j \\
\hline Falta de orientação e supervisão dos trabalhadores quanto à saúde & $6,36 \pm 3,25$ & efg \\
\hline Componentes das equipes de trabalho em número abaixo do ideal & $6,55 \pm 3,33$ & ef \\
\hline Ganho por produtividade & $5,54 \pm 3,65$ & ij \\
\hline Ritmo de trabalho & $5,87 \pm 3,48$ & hi \\
\hline Desconforto ocasionado pelo uso dos equipamentos de proteção individual & $4,89 \pm 3,47$ & k \\
\hline Condições físicas do terminal portuário & $6,79 \pm 3,07$ & e \\
\hline Queda de objetos suspensos & $8,42 \pm 2,47$ & a \\
\hline Trabalho em altura & $7,96 \pm 2,82$ & bc \\
\hline Tráfego de máquinas ** & $7,61 \pm 2,72$ & $\mathrm{~cd}$ \\
\hline Deslocamento do trabalhador sobre as cargas ** & $7,46 \pm 3,03$ & $d$ \\
\hline Instalações elétricas & $6,31 \pm 3,57$ & $\mathrm{fg}$ \\
\hline Empilhamento de carga & $6,72 \pm 3,08$ & ef \\
\hline Escadas de acesso às embarcações & $5,21 \pm 3,56$ & jk \\
\hline
\end{tabular}

* Letras diferentes representam notas médias significativamente diferentes $(p<0,05)$;

** Quesitos com $N=305$, todos os demais itens possuem $N=306$ respondentes.

conferentes de carga $(3,44 \pm 3,03)$ e trabalhadores em vigilância de embarcações $(2,09 \pm 3,75)$.

A variável ritmo de trabalho $(\mathrm{p}=0,01)$ recebeu nota média significativamente maior dos trabalhadores em capatazia $(6,48 \pm 3,25)$ e estiva $(5,67 \pm 3,66)$ do que a dos conferentes de carga $(3,89 \pm 3,22)$.

O item trabalho em altura $(p=0,00)$ recebeu nota média significativamente maior dos trabalhadores em estiva $(8,71 \pm 2,29)$ em relação aos trabalhadores em capatazia $(7,55 \pm 3,05)$, conferentes de carga $(6,83 \pm 2,77)$ e trabalhadores em vigilância de embarcações $(5,91 \pm 3,73)$.

A variável deslocamento do trabalhador sobre as cargas $(\mathrm{p}=0,00)$ recebeu nota média significativamente maior dos estivadores $(8,02 \pm 2,65)$ em relação aos conferentes de carga $(6,28 \pm 3,44)$ e trabalhadores em vigilância de embarcações $(3,09 \pm 4,01)$.

$\mathrm{O}$ item escadas de acesso às embarcações $(\mathrm{p}=0,00)$ recebeu nota média significativamente maior dos trabalhadores em vigilância de embarcações $(7,82 \pm 1,78)$ e estiva $(5,82 \pm 3,29)$ do que a dos trabalhadores em capatazia $(4,42 \pm 3,75)$.

\section{Discussão}

O fato de a maioria dos trabalhadores portuários avulsos ter identificado que existem riscos no seu trabalho demonstra que o ambiente de trabalho portuário é percebido por eles como uma área de risco, uma vez que o risco para acidentes é constante neste cenário 21 . O risco assume o sentido de ser resultante da possibilidade de ocorrência de situações adversas, estando combinada em seu significado, uma previsão com uma indeterminação 7 .

Constatou-se a não associação entre o conhecimento sobre riscos no ambiente portuário e o grau de instrução, demonstrando que as peculiaridades do processo de trabalho portuário são perpetuadas pelos mais velhos aos mais novos na atividade 23 , desse modo o trabalhador raciocina e age de acordo com o seu conhecimento acerca da realidade do contexto no qual se insere 24 .

A não associação entre conhecimento da existência dos riscos no ambiente portuário e categoria profissional, permite supor que a construção de subjetividades e identidades ocorra no 
Valores médios ( \pm desvio padrão) das notas atribuídas pelos trabalhadores portuários avulsos aos riscos no ambiente de trabalho estratificados por categoria profissional. Porto do Rio Grande, Rio Grande do Sul, Brasil, 2006.

\begin{tabular}{|c|c|c|c|c|c|}
\hline \multirow[t]{2}{*}{ Riscos identificados no ambiente de trabalho } & \multirow[t]{2}{*}{$p$ * } & \multicolumn{4}{|c|}{ Categoria } \\
\hline & & Capatazia & Estiva & $\begin{array}{c}\text { Conferentes } \\
\text { de carga }\end{array}$ & $\begin{array}{l}\text { Vigilância de } \\
\text { embarcações }\end{array}$ \\
\hline Ruídos & 0,00 & $7,51 \pm 2,53 b$ & $8,71 \pm 1,85 a$ & $8,00 \pm 2,20 a b$ & $8,45 \pm 1,69 \mathrm{ab}$ \\
\hline Vibrações das máquinas de trabalho & 0,09 & $7,45 \pm 2,64$ & $7,73 \pm 2,78$ & $6,00 \pm 3,29$ & $7,82 \pm 1,94$ \\
\hline Intempéries & 0,24 & $7,82 \pm 2,57$ & $8,35 \pm 2,34$ & $8,11 \pm 2,47$ & $8,82 \pm 0,98$ \\
\hline Temperaturas extremas & 0,86 & $7,57 \pm 2,59$ & $7,44 \pm 2,72$ & $7,33 \pm 2,45$ & $8,09 \pm 1,97$ \\
\hline Substâncias químicas no ar & 0,36 & $7,52 \pm 2,73$ & $7,14 \pm 3,07$ & $7,11 \pm 2,78$ & $8,55 \pm 1,97$ \\
\hline Substâncias químicas líquidas & 0,36 & $6,72 \pm 3,39$ & $6,50 \pm 3,47$ & $5,33 \pm 3,05$ & $7,27 \pm 2,80$ \\
\hline Levantamento manual de carga & 0,00 & $7,18 \pm 2,95$ a & $6,73 \pm 3,21$ & $3,33 \pm 3,48 b$ & $2,82 \pm 3,57 b$ \\
\hline Ferramentas de trabalho & 0,00 & $6,01 \pm 3,29 a$ & $5,55 \pm 3,27 a$ & $2,78 \pm 3,64 b$ & $2,09 \pm 2,74 b$ \\
\hline Falta de orientação e supervisão dos trabalhadores quanto à saúde & 0,84 & $6,28 \pm 3,29$ & $6,59 \pm 3,19$ & $6,28 \pm 2,70$ & $6,00 \pm 3,52$ \\
\hline Componentes das equipes de trabalho em número abaixo do ideal & 0,03 & $6,42 \pm 3,28$ a & $6,90 \pm 3,37$ a & $4,72 \pm 3,04 b$ & $7,82 \pm 3,37$ a \\
\hline Ganho por produtividade & 0,00 & $5,54 \pm 3,62$ a & $6,19 \pm 3,50$ & $3,44 \pm 3,03 b$ & $2,09 \pm 3,75 b$ \\
\hline Ritmo de trabalho & 0,01 & $6,48 \pm 3,25$ & $5,67 \pm 3,66 \mathrm{ab}$ & $3,89 \pm 3,22 c$ & $4,27 \pm 3,26 b c$ \\
\hline Desconforto ocasionado pelo uso dos equipamentos de proteção individual & 0,98 & $4,95 \pm 3,40$ & $4,93 \pm 3,58$ & $4,83 \pm 3,38$ & $5,36 \pm 2,98$ \\
\hline Condições físicas do terminal portuário & 0,43 & $7,10 \pm 2,99$ & $6,51 \pm 3,26$ & $6,56 \pm 3,01$ & $6,45 \pm 1,13$ \\
\hline Queda de objetos suspensos & 0,11 & $8,09 \pm 2,83$ & $8,73 \pm 2,17$ & $8,00 \pm 1,97$ & $9,18 \pm 1,47$ \\
\hline Trabalho em altura ** & 0,00 & $7,55 \pm 3,05 b$ & $8,71 \pm 2,29$ a & $6,83 \pm 2,77 b$ & $5,91 \pm 3,73 b$ \\
\hline Tráfego de máquinas ** & 0,36 & $7,81 \pm 2,79$ & $7,55 \pm 2,60$ & $6,67 \pm 2,25$ & $7,18 \pm 3,82$ \\
\hline Deslocamento do trabalhador sobre as cargas & 0,00 & $7,45 \pm 2,89 \mathrm{ab}$ & $8,02 \pm 2,65$ & $6,28 \pm 3,44 b$ & $3,09 \pm 4,01 c$ \\
\hline Instalações elétricas & 0,25 & $5,92 \pm 3,51$ & $6,74 \pm 3,63$ & $6,33 \pm 3,05$ & $5,55 \pm 4,27$ \\
\hline Empilhamento de carga & 0,08 & $6,56 \pm 3,16$ & $7,15 \pm 2,91$ & $5,94 \pm 2,48$ & $5,18 \pm 4,21$ \\
\hline Escadas de acesso às embarcações & 0,00 & $4,42 \pm 3,75 b$ & $5,82 \pm 3,29 a$ & $5,39 \pm 3,01 \mathrm{ab}$ & $7,82 \pm 1,78 a$ \\
\hline
\end{tabular}

* Letras diferentes representam notas médias significativamente diferentes $(p<0,05)$;

** Quesitos com $N=305$, todos os demais itens possuem $\mathrm{N}=306$ respondentes.

ambiente laboral, que os trabalhadores em geral alicerçam as suas representações de riscos, construindo acerca delas um saber peculiar, formado por experiências anteriores com riscos e sentidos que os mesmos assumem em distintos contextos de trabalho 25.

A visualização da queda de objetos suspensos pelos trabalhadores portuários avulsos demonstra que, no contexto portuário, as cargas em sua maioria são transportadas em contêineres, os quais, podem pesar até trinta toneladas quando cheios 17 . O reconhecimento deste risco pelos trabalhadores, no grupo geral, vai ao encontro do observado no Programa de Prevenção de Riscos Ambientais do OGMO-RG 26.

Os ruídos são reconhecidos também pelos trabalhadores portuários avulsos como importante risco no ambiente portuário. $\mathrm{O}$ ruído define sons desagradáveis, sendo o risco mais comum nos ambientes laborais 27 . No contexto portuário, muitos são os ruídos existentes, tanto a bordo como no cais. A maioria dos guindas- tes/guinchos utilizados emite alarmes sonoros ao se movimentar, sendo esse um dispositivo de segurança obrigatório, conforme o disposto na Norma Regulamentadora 29 18. O tráfego de máquinas, essencial ao transporte das cargas, é freqüente nas operações portuárias, tanto a bordo como no cais, e os ruídos apresentam-se como risco para todas as categorias profissionais 26 .

Em relação às intempéries, o trabalho portuário, por ser efetivado a céu aberto, faz com que os trabalhadores portuários avulsos estejam sujeitos às mais diversas apresentações climáticas, tais como as chuvas, os ventos, a exposição ao sol, as oscilações de temperatura ao longo do dia. As condições de intempéries, mesmo com as roupas especiais para a chuva e as jaquetas para o frio, fornecidas pelo OGMO, nunca poderão ser eliminadas, apenas minimizadas pelo uso de equipamentos de proteção individual, visto se tratar de aspectos que fogem à competência dos profissionais de saúde e segurança que realizam o seu trabalho neste cenário. Este risco também 
é reconhecido para todas as categorias de trabalhadores portuários avulsos, através do frio e calor 26 .

A partir da constatação da diferença significativa na nota média atribuída pelas categorias de trabalhadores portuários avulsos à variável ruídos, considera-se que os estivadores se reconhecem como mais expostos a bordo dos navios do que os trabalhadores em capatazia no cais do porto. Salienta-se que o tráfego de carros e caminhões no cais é grande na maioria das operações, porém, nos navios especializados ou convencionais, há o uso combinado de diferentes equipamentos, tais como as empilhadeiras 23 , e que os exaustores de ar e motores dos navios, guinchos, entre outros, interagem, caracterizando o porão e o convés das embarcações como ambientes extremamente ruidosos.

Em relação ao levantamento manual de carga, reconhecido pelos trabalhadores em capatazia e estiva como risco, este estudo vai ao encontro no disposto pelo Programa de Prevenção de Riscos Ocupacionais do OGMO-RG 26, permitindo concordar-se com outro estudo 17 , que demonstrou serem freqüentes os problemas de músculos, articulações e coluna vertebral entre estivadores tendo como hipótese a dificuldade em manobrar os contêineres e que pode ser observada também na atividade de capatazia.

As ferramentas de trabalho, enquanto risco para os trabalhadores portuários avulsos, permite dizer que os equipamentos utilizados pela estiva na movimentação de cargas, tais como cabos de aço, spreader (quadro posicionador), entre outros, representam um grau de risco muito relevante à vida desses trabalhadores, porque a organização do processo de trabalho deles divide-se entre manual e mecanizado 23 . A capatazia apresenta o mesmo risco que os estivadores, porque para a efetivação do seu trabalho usa os mesmos equipamentos ou equivalentes, sendo maior o risco para acidentes devido aos instrumentos de trabalho nestas atividades.

Os componentes das equipes de trabalho em número abaixo que o ideal, avaliado como risco pelos trabalhadores em vigilância de embarcações, estiva e capatazia, indica que para estes, o trabalho é desenvolvido por um menor número de trabalhadores nas equipes do que a real necessidade da faina, aumentando o seu desgaste, embora o número de componentes das equipes, seja estipulado nas convenções coletivas de trabalho elaboradas por cada sindicato. Isto se relaciona ao fato de que, após a reestruturação produtiva no setor portuário, houve uma redução dos postos de trabalho devido à modernização tecnológica e administrativa 28.
O ganho por produtividade e o ritmo de trabalho, reconhecido como risco pelos trabalhadores em estiva e capatazia, pode ser explicado pelo fato de que estes são os responsáveis diretos pelo que é embarcado/desembarcado, e conseqüentemente, pelo que é ganho nas operações que remuneram de acordo com a produção. Destaca-se ainda que neste contexto, há uma busca incessante para a obtenção de maior ganho e esse ganho por produção constitui uma forma de pressão para haver a aceleração na produtividade, trazendo como conseqüência, um aumento nos riscos 23 , pelo excesso de fadiga que pode interagir com os outros riscos do trabalho, potencializando a ocorrência de acidentes. No porto, pode-se dizer que o ritmo de trabalho se intensificou após a modernização portuária, como reflexo da reestruturação capitalista, que modifica a maneira da realização do trabalho no que tange à sua organização e controle, ocasionando novos ritmos, que em muitas situações são determinados pelas exigências externas do comprador 29 .

O trabalho em altura é reconhecido neste estudo como um risco para os estivadores, pois a bordo das embarcações, seja trabalhando nos guinchos ou no convés, próximo aos porões dos navios especializados em contêineres ou sobre os próprios contêineres, realizam seu trabalho em alturas muito maiores em relação aos demais trabalhadores portuários avulsos, embora este risco também esteja presente nas outras atividades pesquisadas neste estudo 26 .

As escadas de acesso às embarcações foram reconhecidas como um risco pelos trabalhadores em vigilância de embarcações e estiva, pois estes necessariamente precisam ir a bordo da embarcação para ter seu trabalho efetivado, estando mais expostos às quedas que podem ser ocasionadas pelo mau posicionamento das escadas de acesso às embarcações e pela falta de dispositivos de segurança, tais como guardacorpos, contrariando o disposto na Norma Regulamentadora 29 18. Salienta-se que os trabalhadores em vigilância de embarcações também se encontram expostos a este risco conforme o Programa de Prevenção de Riscos Ambientais 26.

\section{Conclusões}

No presente estudo, observou-se que o trabalho portuário avulso, em geral, é um contexto insalubre e perigoso, onde interagem velhos e novos riscos, velhos riscos ergonômicos e de trabalho a céu aberto, novos riscos tecnológicos expressos pela modernização dos portos, que requer agilidade na movimentação portuária, onde a máquina imprime o ritmo de trabalho do homem e 
que tais riscos se apresentam aos trabalhadores em consonância com a atividade por eles desenvolvida. Neste sentido, faz-se necessário que sejam realizadas ações com os trabalhadores, em consonância com a atividade desenvolvida, para formulação de procedimentos que efetivamente diminuam a exposição aos riscos ocupacionais e conseqüentemente, atenuem as doenças e os acidentes que podem ocorrer neste contexto.

Pode-se dizer também que além dos riscos ocupacionais, a própria modalidade de vínculo gera incertezas no que se refere aos rendimentos financeiros dos trabalhadores. A Norma Regulamentadora 2918 é um importante instrumento

\section{Resumo}

Este é um estudo transversal, descritivo, com abordagem quantitativa, realizado no porto do Rio Grande, Rio Grande do Sul, Brasil e objetivou identificar a percepção, em uma amostra com 306 trabalhadores portuários avulsos, sobre risco à saúde no trabalho. A maioria dos trabalhadores portuários avulsos $(93,46 \%)$ reconheceu que existem riscos à sua saúde no trabalho e isso foi independente do grau de instrução $(p=0,44)$, atividade desenvolvida $(p=0,47)$. Os riscos identificados no grupo geral de trabalhadores portuários avulsos foram queda de objetos suspensos $(8,43 \pm 2,47)$, ruídos $(8,06 \pm 2,32)$ e intempéries $(8,05$ $\pm 2,48$ ). Os riscos significativamente diferentes entre as atividades foram: ruídos ( $p=0,00)$, levantamento manual de carga $(p=0,00)$, ferramentas de trabalho $(p=$ $0,00)$, componentes dos ternos em número abaixo do ideal $(p=0,03)$, ganho por produtividade $(p=0,00)$, ritmo de trabalho $(p=0,01)$, trabalho em altura $(p=$ $0,00)$, deslocamento do trabalhador sobre as cargas $(p=0,00)$, escadas de acesso às embarcações $(p=0,00)$. Pode-se corroborar que o trabalho portuário avulso é insalubre e perigoso, e os riscos se apresentam aos trabalhadores em consonância com a atividade por eles desenvolvida.

Riscos Ocupacionais; Saúde do Trabalhador; Trabalhadores para a garantia de saúde e segurança do trabalho portuário, porém, por si só não contempla todos os riscos ocupacionais apresentados neste trabalho. Assim, faz-se necessário ultrapassar a visão da medicina do trabalho e engenharia sanitária, as quais são centralizadas nas normas e técnicas jurídicas com o objetivo de reduzir e inibir os riscos conhecidos que se apresentam no ambiente de trabalho, 30 e seja considerada a saúde do trabalhador como uma responsabilidade própria da saúde pública, que ultrapassa os limites das indústrias e tem como objeto o processo saúde/ doença dos seres humanos e sua relação com o processo de trabalho 31 .

\section{Colaboradores}

J. F. S. Soares, M. R. Cezar-Vaz e V. Z. Costa colaboraram na revisão de literatura, elaboração da metodologia, análise dos resultados e redação do artigo final. R. A. Mendonza-Sassi contribuiu na elaboração da metodologia e análise dos resultados. T. L. Almeida, A. L. Muccillo-Baisch e M. C. F. Soares participaram da análise dos resultados.

\section{Agradecimentos}

Ao Conselho Nacional de Desenvolvimento Científico e Tecnológico (CNPq) pelo financiamento do macroprojeto Saúde do Trabalhador e Conhecimento Sobre Situações de Risco: Um Estudo com Trabalhadores Portuários Avulsos do Município do Rio Grande-RS (Processo no. 485227/2006-1; auxílio 2006/2008), do qual este trabalho é parte integrante; a Lucilene Garcia do Órgão de Gestão de Mão-de-Obra do Trabalho Portuário Avulso do Porto Organizado do Rio Grande (OGMO-RG) pelo acolhimento e disponibilidade. 


\section{Referências}

1. Slovic P. Perception of risk. Science 1987; 236: 280-5.

2. Castiel LD. Lidando com o risco na Era Midiática. In: Minayo MCS, Miranda AC, organizadores. Saúde e ambiente sustentável: estreitando nós. Rio de Janeiro: Editora Fiocruz; 2002. p. 113-33.

3. Luiz OC, Cohn A. Sociedade de risco e risco epidemiológico. Cad Saúde Pública 2006; 22:2339-48.

4. Peres F. Onde mora o perigo? Percepção de riscos, ambiente e saúde. In: Minayo MCS, Miranda AC, organizadores. Saúde e ambiente sustentável: estreitando nós. Rio de Janeiro: Editora Fiocruz; 2002. p. 135-42.

5. Barnett J, Breakwell GM. Risk perception and experience: hazard personality profiles and individual differences. Risk Anal 2001; 21:171-7.

6. Gustafson PE. Gender differences in risk perception: theorical and methodological perspectives. Risk Anal 1998; 18:805-11.

7. Lieber RR, Romano-Lieber NS. O conceito de risco: Janus reinventado. In: Minayo MCS, Miranda AC, organizadores. Saúde e ambiente sustentável: estreitando nós. Rio de Janeiro: Editora Fiocruz; 2002. p. 69-111.

8. Franco T. Padrões de produção e consumo nas sociedades urbano-industriais e suas relações com a degradação da saúde e do meio ambiente. In: Minayo MCS, Miranda AC, organizadores. Saúde e ambiente sustentável: estreitando nós. Rio de Janeiro: Editora Fiocruz; 2002. p. 209-31.

9. Ministério da Saúde. Doenças relacionadas ao trabalho: manual de procedimentos para os serviços de saúde. Brasília: Ministério da Saúde; 2001.

10. Baur X, Yu F, Poschadel B, Veldman W, Vos TK. Health risks by bromomethane and other toxic gases in import cargo ship containers. Int Marit Health, 2006; 57:46-55.

11. Apte MG, Cox DD, Hammond SK, Gundel LA. A new carbon monoxide occupational dosimeter: results from a worker exposure assessment survey. J Expo Anal Environ Epidemiol 1999; 9:546-59.

12. Dimich-Ward H, Dittrick M, Graf P. Survey malathion exposure among elevator and dock workers who handle grain. Can J Public Health 1996; 87:141-2.

13. Heederik D, Cock J, Endlich E. Dust exposure indices and lung function changes in longshoremen and dock workers. Am J Ind Med 1994; 26:497-509.

14. Emmelin A, Nystrom L, Wall S. Diesel exhaust exposure and smoking: a case-referent study of lung cancer among Swedish dock workers. Epidemiology 1993; 4:237-44.

15. Zaebst DD, Clapp DE, Blade LM, Marlow DA, Steenland K, Hornung RW, et al. Quantitative determination of trucking industry workers' exposures to diesel exhaust particles. Am Ind Hyg Assoc J 1991; 52:529-41.

16. Patussi V, De Zotti R, Riva G, Fiorito A, Larese F. Allergic manifestations due to castor beans: an undue risk for the dock workers handling green coffee beans. Med Lav 1990; 81:301-7.
17. Cavalcante FFG, Gomes ACN, Nogueira FRA, Farias JLM, Pinheiro JMR, Albuquerque EV, et al. Estudo sobre os riscos da profissão de estivador do porto do Mucuripe em Fortaleza. Ciênc Saúde Coletiva 2005; 10:101-10.

18. Fundação Jorge Duprat Figueiredo de Segurança e Medicina do Trabalho. Norma Regulamentadora 29: segurança e saúde no trabalho portuário. São Paulo: Fundação Jorge Duprat Figueiredo de Segurança e Medicina do Trabalho; 1998.

19 Kouabenan DR. Beliefs and the perception of risks and accidents. Risk Anal 1998; 18:243-52.

20. Santos Neto AB, Ventilari PSX. O trabalho portuário e a modernização dos portos. Curitiba: Juruá Editora; 2005.

21. Stein AS. Curso de direito portuário: Lei n. 8630/93. São Paulo: LTR Editora; 2002.

22. Silveira FL. Relação do desempenho no concurso vestibular da Universidade Federal do Rio Grande do Sul com diversas variáveis. Estud Aval Educ 1996; 14:83-103.

23. André MM. A consciência de periculosidade e as estratégias defensivas dos portuários avulsos no contexto portuário de Vitória/ES [Tese de Doutorado]. São Paulo: Pontifícia Universidade Católica de São Paulo; 1998.

24. Wisner A. A inteligência no trabalho: textos selecionados da ergonomia. São Paulo: Fundação Jorge Duprat Figueiredo de Segurança e Medicina do Trabalho; 1994.

25. Rangel ML. Saúde do trabalhador: identidade dos sujeitos e representações dos riscos a saúde na indústria petroquímica. Cad Saúde Pública 1993; 9:333-48.

26. Órgão de Gestão do Trabalho Portuário Avulso do Porto Organizado do Rio Grande. Programa de prevenção de riscos ambientais. http://www. ogmo-rg.com.br (acessado em 23/Set/2007).

27. Azevedo AP, Marata TC, Okamato VA, Santos UP. Ruído: um problema de saúde pública (outros agentes físicos). In: Buschinelli JTP, Rocha LE, Rigotto RM, organizadores. Isto é trabalho de gente? Vida, doença e trabalho no Brasil. São Paulo: Editora Vozes; 1993. p. 403-35.

28. Aragão JRNM. Modernização portuária: reflexos na saúde dos trabalhadores portuários avulsos no porto do Rio de Janeiro [Dissertação de Mestrado]. Rio de Janeiro: Escola Nacional de Saúde Pública, Fundação Oswaldo Cruz; 2002.

29. Assunção AA. Uma contribuição ao debate sobre as relações saúde e trabalho. Ciênc Saúde Coletiva 2003; 8:1005-18.

30. Trindade WL. Riscos do trabalho: normas, comentários, jurisprudência. São Paulo: LTR Editora; 1998.

31. Mendes R, Dias EC. Da medicina do trabalho à saúde do trabalhador. Rev Saúde Pública 1991; 25:341-9.

Recebido em 28/Ago/2007

Versão final reapresentada em 19/Out/2007 Aprovado em 13/Nov/2007 